\section{Direito ao território: reconhecimento de direitos sociais às populações que ocupam tradicionalmente territórios de conservação da natureza}

\author{
RIGHTS TO TERRITORY: RECOGNITION OF SOCIAL \\ RIGHTS FOR POPULATIONS TRADITIONALLY \\ OCCUPY TERRITORIES OF NATURE CONSERVATION \\ * Miguel Etinger Araújo \\ ** Renata Vieira Meda
}

Resumo: A pesquisa parte da reflexão acerca da Lei ${ }^{\circ}$ 9.985/ 2000 que instituiu o Sistema Nacional de Unidades de Conservação da Natureza e que regulamenta o artigo $225, \S 1^{\circ}$, incisos I, II, III e VII da Constituição Federal de 1988. Nesse quadro, identificou-se o conjunto de unidades de conservação cuja criação se realiza por ato do Poder Público, dentre as quais, aquelas que não permitem a presença humana, em razão da preservação da natureza, o que implica no processo de desapropriação de populações que tradicionalmente ocupam aqueles territórios. Em uma interpretação literal deste dispositivo, verificou-se a prevalência de políticas públicas ambientais em detrimento dos povos tradicionais, muito embora a garantia dos direitos sociais tenha sido estabelecida pela Constituição Federal de 1988 e reforçada pelo Decreto Federal $\mathrm{n}^{\circ} 6.040 / 2007$, os quais preveem direitos de permanência sobre o território ocupado tradicionalmente. $\mathrm{O}$ artigo contou ainda com estudos de casos concretos, nacionais e internacionais, e decisões judiciais. Ao final deste estudo afirma-se que na criação de unidades de conservação pelo Poder Público baseado em condicionantes socioambientais, os demais direitos consagrados constitucionalmente devem ser observados, reconhecendo-se que a regra é a manutenção das populações tradicionais sobre os territórios que ocupam.

Palavras-chave: Unidades de conservação; Criação; Populações tradicionais; Manutenção.

Abstract: The research part of the reflection on the Law ${ }^{\circ}$ 9.985/2000 that established the National System of Conservation Units and regulating article $225, \S 1^{\circ}$, subsections I, II, III and VII of the Federal Constitution of 1988. In this framework, identified the set conservation units whose creation takes place 
by act of the Government, among which, those that do not allow the human presence, because of the preservation of nature, which implies the expropriation process that populations traditionally occupy those territories. In a literal interpretation of this device, there was a prevalence of environmental policies at the expense of traditional peoples, althought the guarantee of social rights has been established by Federal Constitution of 1988 and reinforced by Federal Decree ${ }^{\circ}$ 6.040/2007, which provide for rights of residence on the territory traditionally occupied. This article also included studies of concrete cases, national and international, and judicial decisions. At the end of this study it is stated that the creation of conservation units by Government based on socio-environmental conditions, other constitutional rights must be observed, recognizing that the rule is the maintenance of traditional populations over the territories they occupy.

Keywords: Conservation units;. Creation; Traditional populations; Maintenance. 


\section{INTRODUÇÃO}

O tema dessa dissertação foi elaborado inicialmente a partir das reflexões sobre a Lei $n^{\circ}$ 9.985/2000 que instituiu o Sistema Nacional de Unidades de Conservação da Natureza que regulamenta o artigo 225, § $1^{\circ}$, incisos I, II, III e VII da Constituição Federal de 1988 - e suas implicações sociais, especialmente sobre territórios tradicionalmente ocupados por populações locais.

A relevância social da Lei que instituiu o conjunto de unidades de conservação trouxe uma maior preocupação a respeito da conexão do reconhecimento identitário e territorial no que diz respeito às populações tradicionais.

Nesse sentido, coloca-se como essencial à discussão o papel do Estado sobre os processos de criação de unidades de conservação, nas quais a Lei ${ }^{\circ}$ 9.985/2000 não permite a manutenção de populações que tradicionalmente ocupavam aqueles espaços territoriais.

A discussão referida relaciona-se a temas recorrentes no âmbito dos órgãos jurisdicionais brasileiros, como conflitos de competência atinentes a entes federativos distintos sobre pretensões diversas, bem como o confronto entre dois bens tutelados.

A problematização da questão territorial às populações tradicionais tornase essencial haja vista que de um lado, a Lei $\mathrm{n}^{\circ}$ 9.985/2000 estabelece que quando criada determinada unidade de conservação que não permita a permanência humana, tem-se o reassentamento de populações tradicionais, ao passo que, os Direitos Fundamentais e a Política Nacional de Desenvolvimento Sustentável dos Povos e Comunidades Tradicionais, estabelecem garantias de direitos a populações tradicionais, dentre as quais o reconhecimento de direitos sociais, territoriais e culturais.

O objetivo principal deste artigo é evidenciar posições que justificam a regra da permanência de populações que ocupam tradicionalmente territórios em que serão criadas unidades de conservação da natureza, e avigorar que o ato de realocação se verifica somente em caráter excepcional.

A pesquisa ora apresentada foi fundamentada em princípios constitucionais, leis infraconstitucionais, doutrina, jurisprudência do ordenamento jurídico pátrio, e estudo de casos com o intuito de estruturar a pesquisa em bases sólidas e adequadas à importância do assunto tratado. A metodologia empregada para o seu desenvolvimento será histórica, dedutiva e estudo de caso, partindo-se de conceitos já preestabelecidos e estruturados, passando por 
estudos de caso, nos quais se pretendeu estudar para se chegar à posição pela permanência de populações que manejam e ocupam tradicionalmente territórios, os quais serão criados unidades de conservação.

Tendo isso em vista, o artigo científico foi estruturado nas seguintes partes:

A Introdução onde se apresenta a elaboração do tema, sua justificativa e problematização, os objetivos, métodos de pesquisa e estrutura.

No Capítulo 1 traz-se uma abordagem histórica dos espaços especialmente protegidos como gênero das chamadas unidades de conservação denominadas tecnicamente pelo Sistema Nacional de Unidades de Conservação da Natureza, que por consequência, remete-se, a problematização da definição jurídica de populações tradicionais.

No Capítulo 2 tem-se a partir de referências legislativas e doutrinárias como um arcabouço para a compreensão da permanência das populações que tradicionalmente ocupam territórios o que pressupõe o seu reconhecimento jurídico.

No Capítulo 3 estuda-se a ideia de território especialmente para as populações tradicionais. Além disso, o capítulo demonstra casos em que serão criadas unidades de conservação sobre territórios ocupados por populações tradicionais; entretanto parcela destas unidades não permite a presença humana, o que implica, na desapropriação por ato do Poder Público. Tais medidas são resultadas de uma política de conservação implicam em detrimento às populações cujos direitos fundamentais, preditos na Constituição Federal de 1988 e por lei infraconstitucional, as quais garantem a manutenção desses povos sobre os territórios. Por fim, o capítulo aborda as formas de precaução do Poder Público ao se criar uma unidade, para assegurar a sobrevivência dessas populações e preservar a natureza, logo, alcançando um duplo objetivo, ilustrado pelo estudo de caso da criação da Reserva Extrativista Renascer, no Estado do Pará.

Por fim, a título de Conclusão, abordou-se algumas exposições a respeito da pesquisa, direcionando a posição para garantir a manutenção de populações tradicionais quando criadas unidades de conservação no território o qual ocupam.

\section{CONSIDERAÇÕES INICIAIS SOBRE UNIDADES DE CONSERVAÇÃO}

O paradoxo em que o Homem necessita do meio ambiente equilibrado para ter uma vida digna e ao mesmo tempo é o seu maior degradador, indica a necessidade de se criar mecanismos que impeçam a ocorrência de um cenário 
de destruição. Dentre estes mecanismos, tem-se na metade do século XIX, a ideia de definir espaços territoriais para a proteção da natureza.

José Afonso da Silva (2004, p. 230) define espaços territoriais especialmente protegidos como porção geográfica do território nacional, sendo públicos ou privados, dotados de atributos naturais relevantes que requerem um regime jurídico de competência do Poder Público, a fim de garantir a sua imodificabilidade e sua utilização sustentada, tendo em vista a preservação e proteção da integridade de toda a diversidade do ecossistema.

Os espaços territoriais especialmente protegidos foram estabelecidos pela Política Nacional do Meio Ambiente instituída pela Lei ${ }^{\circ}$ 6.938, de 31 de agosto de 1981, que dispõe sobre a criação destes pelo Poder Público federal, estadual e municipal, conforme disposto no inciso VI do artigo $9^{\circ}$, bem como pelo inciso III, $\S 1^{\circ}$ do artigo 225 da Constituição Federal de 1988, o qual atribui a competência ao Poder Público em definir tais espaços especialmente protegidos.

No final do século XIX, criaram-se as unidades de conservação, no mundo e no Brasil, vinculadas ao interesse pela preservação de áreas terrestres ou aquáticas detentoras de características naturais excepcionais, bem como pela proteção de exemplares especiais contidos na flora e na fauna.

Nesta senda, José Afonso da Silva (2004, p. 230) estabelece a diferença entre espaços especialmente protegidos e unidades de conservação: "nem todo espaço territorial especialmente protegido se confunde com unidades de conservação, mas estas são também espaços especialmente protegidos". Ademais, Juliana Santilli (2005, p.71) complementa a assertiva afirmando que "os espaços territoriais especialmente protegidos constituiriam gênero, do qual as unidades de conservação seriam espécies".

Juliana Santilli (2005, p. 71) aponta que os espaços territoriais protegidos não compreendem somente as unidades de conservação, mas áreas de preservação permanente, reserva legal, biomas especialmente protegidos elencados no artigo $225 \$ 4^{\circ}$ da Constituição Federal e as reservas da biosfera.

Considerando os espaços especialmente protegidos como gênero das unidades de conservação, Juliana Santilli (2005, p. 66) extrai a noção de que a "conservação e o uso sustentável da biodiversidade tornaram-se o principal objetivo da criação de unidades de conservação da natureza".

Previamente a ideia de unidades de conservação, o marco histórico ocorreu em 1872 nos Estados Unidos com a criação do Parque Nacional de Yellowstone; em razão de sua evolução reproduziu o sistema de unidades de conservação no mundo, como se pode afirmar como mesmo trilhado por Miguel 
Serediuk Milano (2011, p. 04) a "criação do Yellowstone National Park o marco moderno da proteção de áreas naturais contra os processos destrutivos da ação humana".

A partir de 1930 a preocupação com as florestas brasileiras passou a adquirir contornos mais nítidos verificados pelo Decreto n ${ }^{\circ} 23.793$ de 23 de janeiro de 1934 instituindo o Código Florestal (atualmente revogado) que estabeleceu critérios a classificação de florestas e a formas de vegetação, bem como instituiu categorias de manejo para a criação de dada área protegida.

Logo, o Decreto ${ }^{\circ} 1.713$ de 14 de junho de 1937 criou o Parque Nacional de Itatiaia, constituído na área ocupada pela Estação Biológica de Itatiaia, dependência do Jardim Botânico do Rio de Janeiro. Este Decreto incentivou a incorporação de demais áreas de preservação apontadas por José Afonso da Silva (2004, p. 232) quais sejam: Parque Nacional do Iguaçu (Decreto-lei 1.035, de 1939), o Parque Nacional da Serra dos Órgãos (Decreto-lei 1.822, de 1939), Parques Municipais de Almirante/PI, Crato/CE, Boa Nova, Alcobaça, ChiqueChique/BA, dentre outros.

Juliana Santilli (2005, p. 10-11) aponta que as leis ambientais editadas antes dos anos de 1990, ou até a promulgação da Constituição Federal de 1988, eram voltadas para a proteção de ecossistemas e espécies, pautada numa orientação conservacionista, inclusive que as normas que tratavam sobre as unidades de conservação eram muito esparsas e diferenciadas instituindo unidades que nem sequer correspondiam a categorias de unidades de conservação previstas como o atual Sistema Nacional de Unidades de Conservação.

Remanescendo nesta senda, Juliana Santilli (2005, p. 10-11) aponta que as leis editadas nos anos de 1990 e a partir de 2000, rompem com essa orientação preservacionista, instituindo mecanismos e instrumentos de gestão dos bens socioambientais, pautadas numa visão socioambientalista. Neste sentido a autora afirma o período de surgimento do sociambientalismo.

Não se pode olvidar a contribuição de Roberto Guimarães (2001, p. 55) no qual o socioambientalismo foi construído a partir da ideia de que as políticas públicas devem incluir e envolver populações locais, detentoras de conhecimento e de práticas de manejo ambiental.

Nesse contexto de socioambientalismo, Juliana Santilli (2005, p. 15) aponta a evidência da vinculação entre a questão ambiental e a justiça social, baseada no pressuposto que a eficácia social das políticas públicas só se justifica quando inclusas as comunidades locais de modo a promover uma repartição socialmente justa e equitativa dos benefícios derivados da exploração dos recursos naturais. 
No período de advento do socioambientalismo, o Projeto de Lei n ${ }^{\circ} 2.892 /$ 92 foi aprovado pelo Congresso Nacional e originou a Lei $\mathrm{n}^{\circ}$ 9.985, de 18 de julho de 2000 que instituiu o Sistema Nacional de Unidades de Conservação da Natureza, rompendo com a orientação preservacionista, passando a prever mecanismos e instrumentos de gestão dos bens socioambientais, não se limitando apenas a repressão de certas condutas e atividades, que será analisado com maior profundidade no próximo tópico.

\subsection{Sistema Nacional de Unidades de Conservação da Natureza}

O Projeto de Lei ${ }^{\circ} 2.892$ encaminhado para o Congresso Nacional em maio de 1992 adotava uma posição claramente preservacionista cuja preocupação das unidades de conservação refletia somente para o valor das espécies e ecossistemas, para a perda da biodiversidade, deixando-se de atentar às exigências e necessidades humanas, tampouco referindo-se à qualidade de vida dos povos, conforme afirma Juliana Santilli (2005, p. 73).

No contexto apresentado sobre a tramitação do Sistema de Unidades de Conservação, a autora Juliana Santilli (2005, p. 74) aponta que o original projeto instaurou três categorias de unidades de conservação: a) as Unidades de Proteção Ambiental as quais não admitiam a presença humana; b) as Unidades de Manejo Provisório, prevendo, em caráter provisório, a proteção total dos atributos naturais até que fosse definida sua destinação; c) as Unidades de Manejo Sustentável prevendo a "proteção parcial dos atributos naturais, admitindo a exploração de partes dos recursos disponíveis em regime de manejo sustentável”. Neste efeito, verifica-se que as duas últimas categoriais permitiram a presença humana.

Remanescendo nesta senda, vale salientar que as reservas extrativistas incorporadas ao original projeto de lei, anteriormente já haviam sido criadas e regulamentadas pelo Decreto ${ }^{\circ} 98.897$ de 30 de janeiro de 1990 e estabelecidas no artigo $1^{\circ}$ como "espaços territoriais destinados à exploração autossustentável e conservação dos recursos renováveis, por população extrativista". Assim, embora haja a possibilidade da manutenção de permanência das comunidades tradicionais, ainda que transitoriamente, na reserva de recursos naturais, não consta no projeto de lei qualquer definição legal de população tradicional.

Em 1994, o deputado Fábio Feldmann apresentou sua primeira proposta com diversas alterações para o texto original do Projeto de Lei ${ }^{\circ}{ }^{\circ}$ 2.892/1992, sintetizando controvérsias entre preservacionistas e socioambientalistas, conforme apontado por Maurício Mercadante (2001, p. 196-204). 
Juliana Santilli (2005, p. 77) aponta que em 1995, com o afastamento do deputado Fábio Feldmann do Congresso Nacional, a relatoria do Projeto de Lei $n^{\circ}$ 2.892/92 foi distribuída ao Deputado Fernando Gabeira, que dentre novas modificações incluiu dispositivos acerca das comunidades locais, como: i) a participação na criação, implantação e gestão das unidades de conservação; ii) o incentivo a participarem da gestão das unidades de conservação; iii) a garantia de subsistência pela utilização de recursos naturais existentes no interior das unidades, por outro lado, o acesso controlado a esses recursos, meios de subsistência alternativos ou a justa indenização pelos recursos perdidos; iiii) a justa e equitativa distribuição dos custos e dos benefícios decorrentes da criação das unidades entre a sociedade em geral e as comunidades locais afetadas.

O Projeto de Lei ${ }^{\circ}$ 2.892/92 dispôs no inciso XV a definição de população tradicional, no entanto, o conceito foi vetado pelo Poder Executivo, mediante mensagem $n^{\circ} 967$, de 18 de julho de 2000, enviada pelo Presidente da República ao Presidente do Congresso Nacional, haja vista a abrangência da disposição abarcar toda a população brasileira.

Logo às razões de veto de alguns dispositivos do Projeto de Lei n ${ }^{\circ} 2.892 /$ 1992, o Congresso Nacional decreta a Lei $n^{\circ} 9.985$, de 18 de julho de 2000 que regulamenta o artigo $225, \S 1^{\circ}$, incisos I, II, III e VII da Constituição Federal de 1988, e institui o Sistema Nacional de Unidades de Conservação da Natureza, regulamentado no Decreto ${ }^{\circ} 4.340$ de 22 de agosto de 2002.

O Sistema Nacional de Unidades de Conservação da Natureza - SNUC está previsto no artigo $3^{\circ}$ da Lei $n^{\circ}$ 9.985/2000 como "constituído pelo conjunto de unidades de conservação federais, estaduais e municipais". Paulo de Bessa Antunes (2005, p.537) aponta que o SNUC compila-se no conjunto das unidades de conservação federais, estaduais e municipais, cujos objetivos se diferenciam quanto à forma de proteção e usos permitidos, de modo que sejam planejadas e administradas integradas com as demais unidades de conservação.

Inseridas que estão no SNUC, as chamadas unidades de conservação - UC's são entendidas como espaços territoriais públicos ou privados, que por ato do Poder Público, são destinadas ao estudo e à preservação, tendo em vista que são áreas protegidas, definidas geograficamente, para alcançarem objetivos específicos de conservação, conforme artigo $2^{\circ}$, inciso I da lei em comento.

As unidades de conservação integrantes do SNUC dividem-se em dois grupos, com características específicas conforme disposto no artigo $7^{\circ}$ da Lei 
n 9 9.985/2000, quais sejam: as Unidades de Proteção Integral, composta por Estação Ecológica; Reserva Biológica; Parque Nacional; Monumento Natural e Refúgio de Vida Silvestre, e por outro lado: as Unidades de Uso Sustentável, composta por Áreas de Proteção Ambiental; Área de Relevante Interesse Ecológico; Floresta Nacional; Reserva Extrativista; Reserva de Fauna; Reserva de Desenvolvimento Sustentável e Reserva Particular do Patrimônio Natural, compilando, assim, 12 categorias de UC's.

Com efeito, Paulo de Bessa Antunes (2005, p. 533-540) incorpora as disposições já preditas pela Lei $n^{\circ}$ 9.985/2000 ao apontar que as Unidades de Proteção Integral têm por objetivo básico a preservação da natureza, admitindo o uso indireto de seus recursos naturais, salvo os casos previstos na lei do SNUC, ao passo que as Unidades de Uso Sustentável destinam-se à compatibilização entre a conservação da natureza com o uso sustentável de parcela dos seus recursos naturais. Verifica-se que cada modelo de unidades de conservação corresponde a um determinado padrão de limitação de atividades econômicas, sociais, recreacionais, entre outros.

Observa-se que essas áreas protegidas assim denominadas tecnicamente pela Lei ${ }^{\circ}$ 9.985/2000 devem ser conservadas e/ou preservadas, considerandose o tipo de proteção legal específico de cada uma das áreas consideradas individualmente, podendo variar desde a intocabilidade até o uso diário e relativamente intenso.

Um dos pontos cruciais do SNUC refere-se a criação de unidades de conservação prevista no artigo $22, \S 2^{\circ}$ da Lei. Grande parte das atuais demandas para a criação destes espaços especialmente protegidos estão relacionados ao interesse e manifestação da sociedade civil, comunidade científica e/ou órgãos públicos que sensibilizaram-se pela necessidade de estabelecer mecanismos mais robustos para a proteção ao patrimônio natural brasileiro.

Com vistas à criação de uma nova UC, atribui-se ao Poder Público, mediante estudos técnicos, para se determinar a escolha da categoria e dos limites adequados à unidade a ser implantada. Via de regra, serão realizados levantamentos com foco no meio natural, socioeconômico, cultural e fundiário. Tais estudos se permitem detalhar informações sobre comunidades que porventura residam no território proposto e se estas comunidades são caracterizadas como populações tradicionais, se há impactos humanos e como se dão as formas de uso e ocupação do solo, ou seja, são passos ao aprimoramento e continuidade da proposta para a criação da UC. 
Outrossim, o Ministério do Meio Ambiente ${ }^{1}$ aponta que para a criação de UC's, o Poder Público deverá preceder a realização de estudos técnicos e consulta pública para identificar a localização, a dimensão e os limites mais adequados para a criação da unidade.

Após a criação de uma unidade, o Ministério do Meio Ambiente ${ }^{2}$ aponta que faz-se necessário por meio de um planejamento de práticas adotadas dentro desta e no entorno da unidade, a implantação, por um prazo máximo de 5 anos, de um instrumento de gestão denominado plano de manejo, pelos objetivos gerais pelas quais a unidade foi criada.

Ao ser implantada uma unidade, o artigo $27, \S 2^{\circ}$ do SNUC orienta que todas as categorias de unidades de conservação devem dispor de planos de manejo, constituindo-se em documento de grande eficácia para gestão da unidade. Especialmente as categorias: Reservas Extrativistas, Reservas de Desenvolvimento Sustentável, Áreas de Proteção Ambiental e quando couber, as Florestas Nacionais e Áreas de Relevante Interesse Ecológico, lhes são asseguradas à ampla participação da população residente na elaboração, atualização e implantação do plano de manejo, objetivando promover a integração à vida econômica e social das comunidades vizinhas, abrangendo sua área total, bem como a zona de amortecimento e corredores ecológicos.

Em relação ao artigo $27 \S 2^{\circ}$ da Lei do SNUC, merece atenção a crítica feita por Paulo Affonso Leme Machado (2011, p.917) ao que tange a não previsão da participação pública no plano de manejo para a totalidade das categorias de unidades de conservação; tal ponto parece ser um fator considerável no que diz respeito às populações tradicionais localizadas nestes espaços, visto a importância da implantação de UC's em compatibilizar decisões em uma dada unidade.

Diante da abordagem realizada, ao discorrer sobre pontos fundamentais adotados pela Lei $n^{\circ} 9.985 / 2000$, remete-se a observar situações em que estão inseridas populações, as quais serão avaliadas no próximo tópico, pelo reconhecimento de seu conceito jurídico.

\footnotetext{
${ }^{1}$ BRASIL. Ministério do Meio Ambiente. Criação de UC's. Unidades de Conservação. Disponível em: 〈http://www.mma.gov.br/areas-protegidas/unidades-de-conservacao/criacao-ucs $>$. Acesso em: $05 / 05 / 2014$

2 BRASIL. Ministério do Meio Ambiente. Implantação de UC's. Unidades de Conservação. Disponível em: 〈http://www.mma.gov.br/areas-protegidas/unidades-de-conservacao/implantacao-de-ucs〉. Acesso em: 11/06/2014.
} 


\section{CONSIDERAÇÕES PELO RECONHECIMENTO JURÍDICO DE POPULAÇÕES TRADICIONAIS}

As diretrizes do SNUC não dispõem somente acerca da criação de um conjunto de unidades de conservação, mas também pela conservação da sociodiversidade elencada no inciso $\mathrm{X}$ do artigo $5^{\circ}$ do dispositivo como garantia "às populações tradicionais cuja subsistência dependa da utilização de recursos naturais existentes no interior das unidades de conservação meios de subsistência alternativos ou a justa indenização pelos recursos perdidos".

Ao analisar a Lei do SNUC, Juliana Santilli (2005, p. 82) reconhece em diversos dispositivos, o papel e a contribuição das populações tradicionais para a conservação e o uso sustentável da diversidade biológica, como os artigos 18 e 20 da Lei ${ }^{\circ}$ 9.985/2000.

$\mathrm{O}$ inciso XV do artigo $2^{\circ}$ da Lei $\mathrm{n}^{\circ} 9.985 / 2000$ que definia o termo 'populações tradicionais' foi vetado pelo Poder Executivo pela justificativa da Mensagem n 967, de 18 de julho de 2000, mediante seu conteúdo ser tão abrangente que caberia toda a população do Brasil, conforme apontado por Juliana Santilli (2005, p. 83).

Não obstante, a Lei $\mathrm{n}^{\circ}$ 9.985/2000 continuou utilizando as bases do conceito populações tradicionais insertas do dispositivo vetado, exceto no que se refere ao tempo de permanência no local, neste sentido, ratificam Marcia Dieguez Leuzinger e Sandra Cureau (2008, p. 125) ao apontarem que o inciso II, artigo $3^{\circ}$ da Lei $n^{\circ} 11.428$ de 22 de dezembro de 2006 define população tradicional como sendo aquela que vive "em estreita relação com o ambiente natural, dependendo de seus recursos naturais para a sua reprodução sociocultural, por meio de atividades de baixo impacto ambiental", logo, se verifica a mera reprodução do artigo $2^{\circ}$, inciso XV da Lei do SNUC que fora vetado, somente retirado o tempo de permanência da população tradicional no local.

Marcia Dieguez Leuzinger e Sandra Cureau (2008, p. 123) delimitam os seguintes elementos para a caracterização desses povos: "a estreita relação com o ambiente natural; a dependência dos recursos naturais para a sua reprodução sociocultural; a prática de atividades de baixo-impacto ambiental".

Como característica das populações tradicionais, tem-se a importância do território, a relevância do papel das populações desempenhado na 
conservação da biodiversidade, a partir dos conhecimentos tradicionais desenvolvidos e processos produtivos marcados pela economia de subsistência, aos que foram redigidos e publicados pelo Decreto federal $\mathrm{n}^{\circ} 6.040$ de $7 \mathrm{de}$ fevereiro de 2007 que institui a Política Nacional de Desenvolvimento Sustentável dos Povos e Comunidades Tradicionais, estabelecendo a definição destes povos:

Art. $3^{\circ}$ Para os fins deste Decreto e do seu Anexo compreende-se por: I Povos e Comunidades Tradicionais: grupos culturalmente diferenciados e que se reconhecem como tais, que possuem formas próprias de organização social, que ocupam e usam territórios e recursos naturais como condição para sua reprodução cultural, social, religiosa, ancestral e econômica, utilizando conhecimentos, inovações e práticas gerados e transmitidos pela tradição.

No plano internacional, identifica-se a Convenção ${ }^{\circ} 169$ da Organização Internacional do Trabalho - OIT sobre Povos Indígenas e Tribais ratificada pelo Brasil e em vigor, no âmbito interno, em 25 de julho de 2003, mediante o Decreto Legislativo $\mathrm{n}^{\circ} 143$ de 20 de junho de 2002, e publicada pelo Decreto federal $\mathrm{n}^{\circ}$ 5.051 de 19 de abril de 2004, cujo princípio é o respeito e proteção das culturas, costumes e leis tradicionais dos povos indígenas e tribais.

A abordagem da Convenção $\mathrm{n}^{\circ} 169$ da OIT para as populações tradicionais identifica-se, a princípio, pelos sujeitos de direito, aos quais lhes são aplicados as disposições previstas no artigo $1^{\circ}$, sendo definidos três critérios fundamentais, conforme conferido pelo Instituto Socioambiental: a) a existência de condições sociais, culturais e econômicas diferentes de outros setores da sociedade nacional; b) a presença de uma organização social regida total ou parcialmente por regras e tradições próprias; c) a auto-identificação, fundamental no reconhecimento dos grupos tribais que fazem parte de um país.

A princípio a abrangência sobre os sujeitos de direito a que se aplica esta Convenção recai para os povos indígenas e tribais, contudo a Corte Interamericana de Direitos Humanos - CIDH tem manifestado, em diversas oportunidades, no reconhecimento da existência de povos identificados por características sociais, culturais e econômicas diferentes dos outros setores da comunidade nacional, o que implica na obrigação do Estado de oferecer direitos diferenciados para essas populações com o objetivo de garantir os direitos humanos. 
Nesse sentido, tem-se a sentença prolatada pela a $\mathrm{CIDH}^{3}$ em 28 de novembro de 2007, que reconheceu os Povos Saramaka como tribais, haja vista ter um relacionamento profundo e abrangente em relação a sua terra ancestral, o que implica em medidas especiais de acordo com o Direito Internacional dos Direitos Humanos a fim de garantir a sobrevivência física e cultural deste povo.

Partindo-se da premissa de que a CIDH e outras jurisprudências internacionais têm reconhecido como tribais as comunidades cujas condições econômicas, sociais e culturais são diferentes de outros setores da comunidade nacional e considerando que o artigo $1^{\circ}$ da OIT define povos com os mesmo critérios e elementos estabelecidos pelo artigo $3^{\circ}$ do Decreto $n^{\circ}$ 6.040/2007, logo, identifica-se que a Convenção n ${ }^{\circ} 169$ da OIT deve ser aplicada também às populações tradicionais, embora ainda não exista tal reconhecimento pelo Estado brasileiro nesse sentido; para tanto, deve-se exigir medidas em cumprimento ao direito internacional de direitos humanos a fim de garantir a sobrevivência física e cultural destes povos.

No plano estritamente doutrinário, o reconhecimento de populações tradicionais vem sendo construído a partir de variados primas que entretanto se orientam por requisitos mínimos encontrados nas leis em vigor acerca do tema, em especial a característica dessas populações guardarem um estilo de vida relevante para a proteção da natureza e manutenção da diversidade biológica, utilizando-se, para tanto, de atividades de baixo-impacto.

No plano antropólogo, Antonio Carlos Diegues (1999, p.21-22) aponta elementos característicos de determinado grupo tradicional:

Pela dependência frequente, por uma relação de simbiose entre a natureza, os ciclos naturais e os recursos naturais renováveis a partir dos quais se constroem um modo de vida; conhecimento aprofundado da natureza e de seus ciclos que se reflete na elaboração de estratégias de uso e de manejo dos recursos naturais; pela noção de território ou espaço onde o gripo social se reproduz econômica e socialmente; pela moradia e ocupação desse território por várias gerações, ainda que alguns membros individuais possam ter se deslocado para os centros urbanos e voltados para a terra de seus antepassados; pela importância das atividades de subsistência, ainda que a

3 CORTE InTERAmeriCANA DE DEREChOS humanos. Caso del Pueblo Saramaka Vs Surinam. Sentencia del 28 de noviembre de 2007. Disponível em: <http://util.socioambiental.org/ inst/esp/consulta_previa/sites/util.socioambiental.org.inst.esp.consulta_previa/files/cidhsaramaka\%20vs\%20surinam.pdf>. Acesso em 18/06/2014. 
produção de mercadorias possa estar mais ou menos desenvolvida, o que implica uma relação com o mercado; pela reduzida acumulação de capital; pela importância das simbologias, mitos, rituais associados à caça, à pesca e a atividades extrativistas; pela tecnologia utilizada que é relativamente simples, de impacto limitado sobre o meio ambiente. Há uma reduzida divisão técnica e social do trabalho, sobressaindo o artesanal, cujo produtor (e sua família) domina o processo de trabalho até o produto final; pelo fraco poder político, em que reside com os grupos e poder dos centros urbanos; pela auto-identificação ou identificação pelos outros de se pertencer a uma cultura distinta das outras.

Ainda, Antonio Carlos Diegues (1999, p.03) identifica determinados grupos como tradicionais, chamados em geral de camponeses, que resultam de uma miscigenação dos povos que compreendem os caiçaras, comunidades pantaneiras, ribeirinhas, pescadores artesanais, pequenos produtores litorâneos, os quais guardam um isolamento geográfico e um modo de vida particularizado pela dependência aos recursos naturais.

Com efeito, ainda Paul E. Little (2002, p.86) aponta que as populações tradicionais se inserem em dinâmicas e contextos históricos, quando afirma que as constantes mudanças históricas são provocadas por processos seculares de fronteiras em expansão e pelos múltiplos tipos de territórios sociais que produziram, demonstrando que o termo tradicional refere-se a realidades fundiárias plenamente modernas, ou ainda pós-modernas do século XXI. Dessa forma, o termo tradicional associa-se a tradições culturais que se mantém e se atualizam mediante uma dinâmica de constante transformação.

Não se pode olvidar, a contribuição de Henyo Trindade Barreto Filho (2006, p.110) o qual assinala que a noção de populações tradicionais produz efeitos nas disputas simbólicas constituídas por lutas internas em torno do acesso aos fatores de produção, bem como nos processos políticos que influenciam os direitos territoriais.

Portanto, determinados os elementos para se reconhecer juridicamente o conceito de populações tradicionais, que pressupõem desde a identificação de um grupo distinto da sociedade, passando pela dependência dos ciclos dos recursos naturais por uma gestão compartilhada, até os limites do território em que se produzem, tem-se a necessidade de reconhecer o espaço territorial em que ocupam, que vai além de uma interpretação teleológica, o qual será esclarecido no próximo capítulo. 


\section{O TERRITÓRIO COMO ANÁlise SOCIAL PELAS POPULAÇÕES TRADICIONAIS}

Parte-se de uma análise sobre o conceito de território em que identificase interpretações diversas, dentre elas a noção de territórios para as populações tradicionais, que vai além de uma interpretação teleológica.

A ideia de território como espaço territorial utilizado é definido por Berta Becker (2006, p. 51) a partir de dois campos distintos: de um lado a apropriação efetiva do espaço, e de outro, a utilização deste como meio para a prática de atividade.

Rogério Haesbaert (2005, p. 6774-6792) indica diferentes análises acerca do termo territorialidade:

a) Territorializações mais fechadas, quase "uniterritoriais" no sentido de incorporarem a correspondência entre o poder público e identidade cultural, ligadas ao fenômeno do territorialismo, como nos territórios defendidos por grupos étnicos que se pretendem culturalmente homogêneos, não admitindo a pluralidade territorial de poderes e identidades; na sobreposição "encaixada" de territorialidades político-administrativas);

d) Territorializações efetivamente múltiplas - uma "multiterritorialidade" em sentido estrito, construída por grupos ou indivíduos que constroem seus territórios na conexão flexível de territórios multifuncionais e multiidentitários.

Dentre as territorialidades apresentadas, destaca-se a alínea a), que remete a perceber que o reconhecimento identitário dos grupos tradicionais incorpora a ideia de territorialidade, no sentido de transcender a ocupação geográfica, expressando os vínculos sociais e simbólicos.

Nesta senda de ocupação tradicional, Michel Foucault (2003, p. 213) aponta que seria necessário fazer uma 'história de espaços' ao qual se equivaleria a uma 'história de poderes' que estudasse desde as grandes estratégias da geopolítica até as pequenas táticas do habitat, passando pelas implantações econômico-políticas, o que remete a perceber que o problema dos espaços aparece como problema histórico-político.

Logo, Dirce Koga (2003, p. 55) aponta que a noção de território sobrepõe a ideia do localismo reducionista, tendo em vista que a própria história e as condições de vida existentes naquele espaço remetem a uma análise social do território. 
É nesse sentido de que a noção do território vai além do localismo reducionista, se traduzindo na manutenção e condições de vida de grupos de populações bastante antigas, as quais compreendem o território, sobretudo, como algo indispensável à sua reprodução física e cultural.

Neste quadro, Nicolao Dino Costa Neto (2013, p. 105) define territorialidade para as populações tradicionais, como um conjunto de fatores que transcendem o mero aspecto de ocupação geográfica, para expressar a existência de vínculos sociais e simbólicos, onde se predomina o uso sustentável e de baixo impacto dos recursos naturais, o desempenho de práticas culturais não predatórias e a gestão compartilhada de recursos naturais.

Outrossim, corroboram Marcia Dieguez Leuzinger e Sandra Cureau (2008, p.129) ao apontarem que a importância da noção de território para os grupos tradicionais não reside na relação entre territorialidade e posse imaterial, tampouco em função do tempo de ocupação, mas em função dos "usos, costumes e tradições reproduzidos pelos povos tradicionais, em geral a partir da tradição oral, e que traduzem uma ocupação coletiva do espaço, onde prevalece o uso e a gestão compartilhada dos recursos naturais".

A territorialidade para as populações tradicionais é destacada por Paul E. Little (2002, p.3-4) a partir de três elementos: a) regime de propriedade comum; b) sentido de pertencimento a um lugar específico; c) profundidade histórica da ocupação guardada na memória coletiva, embora tais elementos serem comuns para outros povos tradicionais em planos socioculturais.

Juliana Santilli $(2005$, p.92) ao dissertar sobre as populações tradicionais e suas relações com o território afirma que o conceito de território deve ser compreendido como o espaço necessário à reprodução física e cultural de cada povo tradicional, considerando ainda as formas diferenciadas de uso e apropriação do espaço territorial.

Para as comunidades de quilombos, a importância da territorialidade foi destacada no estudo denominado "Comunidades Quilombolas: Direito à Terra", mediante um regime de propriedade comum, diante de um manejo territorial que obedece a sazonalidade dos recursos naturais, como apontada por Carlos Ari Sundfeld (2002, p. 78-79).

Ao passo que para as comunidades de quilombos, a visão da territorialidade é compreendida não como uma propriedade particular, mas como

${ }^{4}$ SUNDFELD, Carlos Ari (Org.). Comunidades quilombolas: direito à terra. Brasília: Fundação Cultural Palmares/Ministério da Cultura, Editorial Abaré, 2002. 
um bem de uso comum, a ideia de territorialidade para os indígenas segundo Marcia Dieguez Leuzinger e Sandra Cureau (2008, p. 128-129) refere-se ao modo tradicional de sua ocupação e a utilização da terra e ao modo tradicional de produção, conforme seus costumes típicos.

A territorialidade para os indígenas e comunidades quilombolas ganha formatos diferentes quanto comparados às populações tradicionais, em caráter geral, haja vista que conforme Juliana Santilli (2005, p. 49) os povos indígenas e quilombolas gozam de um peculiar regime jurídico constitucional face as populações tradicionais em geral.

Em face das populações tradicionais não gozarem de um peculiar regime jurídico como os povos indígenas e quilombolas, a problemática questão atinente às populações tradicionais se verifica ao que diz respeito a realocação destas para outro local, quando da criação de determinada unidade de conservação a qual não permita a presença humana, conforme aponta Marcia Dieguez Leuzinger e Sandra Cureau (2008, p. 132).

Portanto, tem-se o território físico como elemento de extrema importância as populações tradicionais reproduzido na existência física, cultural e sobrevivência, no entanto, diante de uma sociedade constituída pela diversidade de culturas o que pressupõe diversas análises territoriais, identificam-se conflitos, como as desapropriações de populações tradicionais em territórios de conservação, ao qual se buscará no próximo tópico, priorizar a manutenção destes grupos, mediante um arcabouço consagrado constitucionalmente e por leis infraconstitucionais.

\subsection{A Permanência de Populações Tradicionais em Unidades de Conservação Face a Desapropriação}

Um dos questionamentos que se faz acerca da Lei do SNUC, diz respeito à desapropriação de populações que tradicionalmente ocupam e manejam territórios criados como unidades de conservação, previsto no artigo $42^{5}$ da Lei do SNUC.

A título de exemplos de decorrência da criação de UC's as quais não permitem a presença de populações tradicionais, Juliana Santilli (2005, p.106) destaca as populações tradicionais do Masai do Quênia, expulsas de suas terras

\footnotetext{
Art. 42. As populações tradicionais residentes em unidades de conservação nas quais sua permanência não seja permitida serão indenizadas ou compensadas pelas benfeitorias existentes e devidamente realocadas pelo Poder Público, em local e condições acordados entre as partes.
} 
para a implantação de um parque nacional; a implantação do Parque Nacional Krüger na África do Sul que implicou na desapropriação de grupos tradicionais; e no Brasil, a retirada de populações para a implantação da unidade de conservação - Estação Ecológica de Anavillhanas no Amazonas.

Sob a desapropriação de populações residentes em unidades de conservação as quais sua permanência não seja permitida, tem-se no plano nacional, o conflito instaurado no Parque Nacional da Tijuca, no município do Rio de Janeiro. Trata-se de Ação Civil Pública, sob os autos $n^{\circ} 0007478$ 70.2012.4.02.5101, ajuizada na $1^{\mathrm{a}}$ Vara Federal da Seção Judiciária do Rio de Janeiro, proposta pelo Ministério Público Federal em face dos seguintes requeridos: Leonor Dias Gomes, União Federal, Município do Rio de Janeiro e ICMBio - objetivando dentre outras condenações, a condenação da primeira requerida a desocupar o imóvel federal localizado na Estrada da Cascatinha, $\mathrm{n}^{\circ}$ 850, casa 2, próximo a "Fazenda" no Bosque dos Esquilos, Alto da Boa Vista, localizada no Parque Nacional da Tijuca, do Município.

Em sentença proferida em 30 de outubro de 2013, o Juiz Federal Mauro Souza Marques da Costa Braga, julgou a Ação Civil Pública procedente para dentre outros pedidos condenar a primeira requerida a desocupar o imóvel federal, bem como a condenação do Município do Rio de Janeiro em reassentá-la em área localizada fora dos limites do Parque Nacional da Tijuca, por se tratar de Unidade de Conservação de Proteção Integral, nos termos do $\operatorname{artigo~} 8^{\circ}$ e $11^{\circ}$ da Lei do SNUC.

A decisão judicial apresentada é emblemática a este trabalho por tratarse de categorias de unidades de conservação que não permitem a presença de populações tradicionais, as quais se fazem embasadas pelo artigo 42 da Lei do SNUC que consagra um duplo direito a estas populações, qual seja primeiramente, o direito de serem indenizadas ou compensadas pelas benfeitorias existentes, e, cumulativamente, o direito de serem reassentadas pelo Poder Público.

Ainda no plano legislativo, os artigo 35 e seguintes do Decreto ${ }^{\circ} 4.340 /$ 2002 dispõem acerca do processo indenizatório referente às populações tradicionais em unidades de conservação, que quando não permitida a sua permanência, deverá ser respeitado o modo de vida e as fontes de sobrevivência, sendo que o Poder Público deverá ainda contabilizar o valor das benfeitorias realizadas, a título de compensação, na área de reassentamento.

Identifica-se que a não permanência das populações quando da criação de unidades, somente se justificará constitucionalmente, segundo os artigos 215 
e 216, os quais pressupõem impactos pelas atividades praticadas por populações, quando o ecossistema local não puder suportar, logo, em casos específicos, a presença de populações implicará na disruptura do ecossistema, causando prejuízos a própria população que depende dos ciclos da natureza para a sua sobrevivência, conforme apontam Marcia Dieguez Leuzinger e Sandra Cureau (2008, p. 132).

Como consequência da desapropriação dos territórios ocupados, Marcia Dieguez Leuzinger e Sandra Cureau (2008, p. 132) afirmam que a realocação das populações tradicionais, em local distinto do que tradicionalmente ocupavam, resulta, em geral, na dispersão de seus componentes tradicionais.

Deborah de Magalhães Lima (2002, p. 37-43) aponta que a realocação das populações tradicionais, ou ainda, a exclusão delas em unidades de conservação é fruto de políticas de conservação que desconsideram o seu papel na conservação de seus habitats naturais e simplesmente promovem a discriminação social, e atribui a compensação social como forma de mitigar este efeito negativo.

Embora a Lei do SNUC preveja algumas medidas voltadas para a promoção da equidade social e para a compensação social das populações tradicionais, é importante destacar que as populações tradicionais, principalmente a partir da promulgação da Constituição Federal de 1988, conquistaram direitos fundamentais preditos em princípios e direitos que garantem a sua manutenção no território em que residem, segundo aponta Patrícia Fernandes de Oliveira Santos (2013, p. 549):

Ora se a Constituição garante a existência digna do ser humano, se a preservação da natureza é para benefício do ser humano, se a existência de populações tradicionais ajuda a conservar a natureza e se parte da dignidade dessas populações somente se alcançam quando mantidas em seu território de origem, conclui-se, então, que não tem porque tirá-las de seu território quando da criação de unidade de conservação. Pelo contrário, a manutenção delas é primordial para a existência digna dessas populações.

Nessa perspectiva, a referida autora (2013, p. 548-549) aponta que os direitos conquistados pelas populações tradicionais, consagrados constitucionalmente, particularmente no que diz respeito ao direito de permanência no território, se baseiam especialmente no princípio da dignidade da pessoa humana, tendo em vista que o território é elemento primordial para a existência digna desses grupos. 
Outrossim, na perspectiva infraconstitucional, a fim de garantir os direitos às populações tradicionais, a desfavor da desapropriação, tem-se o Decreto $n^{\circ}$ 6.040/2007 que instituiu a PNPCT a qual dentre várias ações para a proteção das populações tradicionais, prevê a manutenção destas nos territórios em que ocupam, conforme estabelecido no artigo $2^{\circ}$ e inciso I do artigo $3^{\circ}, \operatorname{logo}, o$ referido Decreto reconhece os direitos territoriais como garantia às populações tradicionais, mediante a prática de ações e atividades voltadas a importância dos direitos humanos, conforme disposto no inciso XII, art. $1^{\circ}$. Portanto, partindo da premissa que o território trata-se de elemento fundamental para a dignidade destes povos, enseja-se a manutenção das populações em seus habitats.

Pelo objetivo de proteger o meio ambiente, concomitantemente pela proteção à manutenção das populações que tradicionalmente ocupam unidades de conservação, tem-se a Medida Cautelar Inominada sob os autos $\mathrm{n}^{\circ}$ 2006.39.03.003102-0, e Ação Civil Pública sob o n 2007.39.03.000042-0, ambas tramitadas na Vara Única da Subseção Judiciária de Altamira, Estado do Pará, proposta pelo Ministério Público Federal em face do Estado do Pará, Instituto Brasileiro do Meio Ambiente e Recursos Naturais Renováveis - IBAMA e o Instituto Nacional de Colonização e Reforma Agrária - INCRA, com o objetivo de assegurar a criação da RESEX Renascer e impedir a sobreposição de unidades de conservação estaduais com finalidades conservacionistas incompatíveis com a garantia de direitos das populações tradicionais.

Ocorre que, os Requeridos não estavam dispostos a ceder à criação da RESEX Renascer que se baseia na proteção do meio ambiente, no uso sustentável dos recursos naturais, bem como na regularização fundiária em benefício das populações tradicionais, pleiteando, sob o mesmo espaço territorial, a criação da Floresta Estadual Amazônia e da Área de Proteção Ambiental Santa Maria de Prainha, as quais não consideram os mesmos elementos da RESEX, mas sim o uso sustentável dos recursos florestais sob o ponto de vista econômico.

No caso apresentado de superposição de medidas relativas à implantação de unidades de conservação sob o mesmo espaço territorial, o Juiz Federal Claudio Henrique Fonseca de Pina reconheceu pela implantação da RESEX por atender a dois critérios de relevante interesse público tais como: a utilização sustentável dos recursos naturais e a regularização fundiária, garantindo às populações extrativistas tradicionais a posse de áreas necessárias à sua subsistência física e cultural. Assim, em 20 de julho de 2009 foi publicada a r.decisão para implantar-se a Reserva Extrativista Renascer no Estado do Pará. 
A referida decisão é ponto significativo a este trabalho por abordar o critério de harmonização no exercício da competência comum a entes federativos para se criar unidades de conservação, partindo-se da ideia da prevalência do interesse geral de proteção ao meio ambiente vinculado ao interesse pelos direitos das populações locais.

Diante das pontuais decisões judiciais expostas, de um lado a que cingiuse pela desapropriação de populações tradicionais em unidades cuja presença humana não seja permitida, e por outro lado, a decisão judicial que implementou melhor categoria de UC a fim de proteger o meio ambiente e assegurar a manutenção e sobrevivência das populações tradicionais; pauta-se neste contexto, que, para a efetivação dos direitos sociais às populações tradicionais deverá haver uma ponderação entre a garantia dos direitos fundamentais e a escolha da categoria de criação de UC.

Logo, a proteção constitucional e infraconstitucional que detém as populações tradicionais deve servir de parâmetro para que o Poder Público escolha a categoria de unidade de conservação a ser implantada, de forma a não haver violação dos direitos humanos, em especial os sociais, que será centro de estudo do próximo tópico.

\section{CONSIDERAÇÕES FINAIS}

A partir do advento do socioambientalismo, as leis ambientais editadas nos anos de 1990 e a partir de 2000 passaram a instituir mecanismos de gestão dos bens socioambientais evidenciando ações de vinculação de proteção ao meio ambiente e proteção às populações tradicionais.

O Projeto de Lei ${ }^{\circ}$ 2.898/92 deu origem à Lei n ${ }^{\circ}$ 9.985/2000 que instituiu o SNUC, estabelecendo garantias adequadas de proteção às unidades de conservação federais, estaduais e municipais, por se tratarem de espaços territoriais especialmente protegidos com características naturais relevantes, com objetivos de conservação e limites definidos.

A referida Lei ainda identifica a contribuição das populações tradicionais para a conservação e uso sustentável da diversidade biológica, no entanto, não reconhece expressamente garantias relativas à manutenção destas, tendo em vista que quando o Poder Público criar unidade de conservação sobre o território em que tradicionalmente ocupam (art. 42), está previsto, em caráter transitório, o reassentamento destes povos. 
Por outro lado, dentre as várias medidas relativas a proteção de populações tradicionais, está o Decreto $n^{\circ}$ 6.040/2007 que instituiu a PNPCT que dispõe acerca da garantia de permanência das populações que tradicionalmente ocupam territórios (inc. I, art. $3^{\circ}$ ), mediante ações e atividades voltadas a importância dos direitos humanos (inc. XII, art. $1^{\circ}$ ) para o reconhecimento, fortalecimento dos direitos territoriais, sociais, ambientais, econômicos e culturais (art. $2^{\circ}$ ) destes grupos tradicionais.

Identificou-se uma aparente contrariedade entre a Lei do SNUC que preza pela proteção ao meio ambiente quando criada determinada unidade implicado no reassentamento de populações tradicionais, ao passo que, a PNPCT estabelece garantias de direitos a populações tradicionais, dentre as quais o reconhecimento de direitos territoriais, logo, reconhece a manutenção destas sobre o território em que ocupam e manejam.

Na situação do eventual confronto, incabível entre uma Lei e um Decreto, pois este último seria considerado ilegal, considera-se existirem dois bens tutelados: a proteção do meio ambiente e a proteção à populações tradicionais. A solução é se pautar pelas previsões constitucionais baseadas em condicionantes socioambientais que pressupõe a interpretação sistêmica dos direitos ambientais, sociais e culturais, e não uma posição preservacionista que privilegia a conservação das espécies e do ecossistema, isoladamente.

Foram expostas pontuais decisões judiciais na presente dissertação, sendo de um lado, as que se cingiram pela desapropriação de populações tradicionais em unidades cuja presença humana não seja permitida, e por outro lado, a decisão judicial que implementou determinada categoria de UC a fim de proteger o meio ambiente e assegurar a manutenção e sobrevivência das populações tradicionais.

Pauta-se neste contexto que, havendo confronto pela manutenção das populações tradicionais nas áreas em que ocupam, a solução se dará por uma ponderação entre a garantia dos direitos fundamentais e a categoria de criação de UC, isto é, uma interpretação sistêmica dos direitos ambientais, sociais e culturais que permitem a efetivação dos direitos sociais, em especial o reconhecimento de direitos territoriais à estes grupos.

Como forma de avigorar a posição acerca da manutenção das populações que tradicionalmente ocupam territórios de conservação da natureza, reconhecese que os dispositivos do artigo 42 , caput, $\S 1^{\circ}, 2^{\circ}$ e $3^{\circ}$ da Lei $n^{\circ} 9.985 / 2000$, os quais dispõem acerca do reassentamento quando não permitida a permanência de populações, encontram-se topograficamente nas Disposições Gerais e 
Transitórias da Lei federal, logo, tais dispositivos implicam em regularizar situações discrepantes das normas constitucionais permanentes, o que pressupõe situações específicas, ou excepcionais. Portanto, ratifica-se que a regra se estabelece pela manutenção das populações tradicionais que ocupam territórios nos quais foram e serão criados as unidades de conservação.

Por fim, conclui-se que, seja pela interpretação dos direitos fundamentais assegurados constitucionalmente a grupos tradicionais, seja por leis infraconstitucionais pela garantia à proteção dos direitos das populações tradicionais, e ainda, seja pelo caráter excepcional conferido ao reassentamento de populações previsto no art. 42 da Lei n ${ }^{\circ} 9.985 / 2000$, o reconhecimento desses direitos parece fundamental, especialmente porque a manutenção destes grupos tradicionais no território em que vivem constitui elemento primordial da dignidade.

A regra da permanência dessas populações em territórios que tradicionalmente ocupam e manejam ainda se justifica vez que sua presença não causa grande impacto de degradação ao meio ambiente, pelo contrário, o manejo tradicional dos recursos naturais contribui para a preservação ambiental, o que se deve atentar é pela não ocorrência de um inchaço populacional nestes territórios de conservação.

Em face da estabelecida regra de permanência das populações tradicionais nos territórios que ocupam, o ente federativo competente, ao criar unidade de conservação, deverá estar baseado em condicionantes socioambientais, logo, escolhendo a categoria de unidade de conservação compatível com a proteção do meio ambiente e com a manutenção de populações, sendo o reassentamento somente utilizado em caráter de exceção e devidamente justificado.

\section{REFERÊNCIAS}

ANTUNES, Paulo de Bessa. Direito Ambiental. $8^{\text {a }}$ Ed. Rio de Janeiro: Lúmen Júris, 2005.

BECKER, Berta. (Coord.). Logística e ordenamento do território: subsídio a elaboração da Política Nacional de Ordenamento do Território PNOT. Brasília: Ministério da Integração Nacional, 2006.

BRASIL. Justiça Federal Seção Judiciária do Rio De Janeiro ( $1^{\text {a }}$ Vara Federal). Ação Civil Pública n ${ }^{\circ}$ 0007478-70.2012.4.02.5101. Requerente: 
Ministério Público Federal. Requeridos: Leonor Dias Gomes, União Federal, Município do Rio de Janeiro e ICMBio. Juiz Federal: Mauro Souza Marques da Costa Braga, 30/10/2013. Disponível em: <http://procweb.jfrj.jus.br/portal/ consulta/resconsproc.asp>. Acesso em: 29/07/2014.

BRASIL. Ministério do Meio Ambiente. Criação de UC's. Unidades de Conservação. Disponível em: <http://www.mma.gov.br/areas-protegidas/ unidades-de-conservacao/criacao-ucs>. Acesso em: 05/05/2014.

BRASIL. Tribunal Regional Federal ( $1^{\mathrm{a}}$ Região). Ação Civil Pública ${ }^{\circ}$ 2007.39.03.000042-0. Autor: Ministério Público Federal. Réu: Estado do Pará; União Federal; IBAMA; INCRA. Juiz Federal: Cláudio Henrique Fonseca de Pina. Altamira, 29/05/2009. Disponível em: <https:// processual.trf1.jus.br/consultaProcessual/processo.php?proc $=2007390$ 30000420\&secao=ATM\&pg=1\&trf1_captcha_id=756f0253877375008 108ec997a807378\&trf1_captcha=q632\&enviar=Pesquisar $>$. Acesso em: 15/ $04 / 2014$.

\section{CORTE INTERAMERICANA DE DIREITOS HUMANOS. Caso Del} Pueblo Saramaka Vs. Suriname. Sentencia del 28 de noviembre de 2007. Disponível em: <http://www.corteidh.or.cr/docs/casos/articulos/ seriec_172_esp.pdf>. Acesso em 18/06/2014.

COSTA NETO, Nicolao Dino. Conflito de Interesses na criação de unidades de conservação e repartição de competências. São Paulo: Revista de Direito Ambiental, 2013.

COSTA NETO, Nicolao Dino. Conflito de interesses na criação de unidades de conservação e repartição de competências. In: Revista de Direito Ambiental.

CAPPELLI, Sílvia; LECEY, Eladio. São Paulo: Revista dos Tribunais, 2013.

DIEGUES, Antonio Carlos Sant'Ana. O Mito Moderno da Natureza Intocada. Editora Hucitec: São Paulo,1998.

DIEGUES, Antonio Carlos. Biodiversidade e Comunidades Tradicionais no Brasil. São Paulo: Nupaub, USP, 1999. 
DIEGUES, Antonio Carlos. O mito moderno da natureza intocada. São Paulo: Hucitec, 2001.

FOUCAULT, Michel. Microfísica do poder. São Paulo: Graal, 2003.

GUIMARÃES, Roberto. A ética da sustentabilidade e a formulação de políticas de desenvolvimento. In: DINIZ, Nilo; SILVA, Marina; VIANA, Gilney (Orgs.). O desafio da sustentabilidade: um debate socioambiental no Brasil. São Paulo: Editora Fundação Perseu Abramo, 2001.

HAESBAERT. Rogério. Da desterritorialização à multiterritorialidade. In: Encontro de Geográfos da América Latina 10, 2005, São Paulo. Anais do X Encontro de Geográfos da América Latina, São Paulo: 2005.

KOGA, Dirce. Medidas de cidades: entre territórios de vida e territórios vividos. São Paulo: Cortez, 2003.

LEUZINGER, Márcia Dieguez; CUREAU, Sandra. Direito Ambiental. Ed. Elsevier, Rio de Janeiro, 2008.

LIMA, Deborah de Magalhães. Ética e política ambiental na Amazônia contemporânea. In: LITTLE, Paul E. Territórios Sociais e povos tradicionais no Brasil: por uma antropologia da territorialidade. Brasília: Universidade de Brasília, Departamento de Antropologia, 2002.

MACHADO, Paulo Affonso Leme. Direito Ambiental Brasileiro. 19ª Ed. São Paulo: Malheiros Editores, 2011.

MERCADANTE, Maurício. Democratizando a Criação e a Gestão de Unidades de Conservação da Natureza: a Lei 9.985, de 18 de julho de 2000. In: Revista de Direitos Difusos. Ano I, Vol.5: florestas e unidades de conservação. São Paulo: Esplanada, 2001.

MILANO, Miguel Serediuk. Unidades de conservação - técnica, lei e ética para a conservação da biodiversidade. In: Direito ambiental das áreas protegidas - o regime jurídico das unidades de conservação. Coord. Antônio Herman Benjamin. Rio de Janeiro: Forense Universitária, 2001. 
SANTILLI, Juliana. Socioambientalismo e novos direitos: proteção jurídica à diversidade biológica e cultural. São Paulo: Peirópolis, Instituto Socioambiental e Instituto Internacional de Educação do Brasil, 2005.

SANTOS, Patrícia Fernandes de Oliveira. A Lei de SNUC à luz dos movimentos ambientalistas e o direito de permanência das populações tradicionais. In: BENJAMIN, Antonio Herman; IRIGARAY, Carlos Teodoro José Hugueney; LECEY, Eladio; CAPPELLI, Sílvia. Licenciamento Ética e Sustentabilidade. $18^{\circ}$ Congresso de Direito Ambiental, 2013.

SILVA, José Afonso da. Direito Ambiental Constitucional. $5^{\text {a }}$ Ed. São Paulo: Malheiros: 2004.

SUNDFELD, Carlos Ari (Org.). Comunidades quilombolas: Direito à terra. Brasília: Fundação Cultural Palmares/Ministério da Cultura/Editorial Abaré, 2002.

Artigo recebido em: 28/09/2014 Aprovado para publicação em: 31/10/2014

Como citar: ARAUJO, Miguel Etinger. MEDA, Renata Vieira. Direito ao território: reconhecimento de direitos sociais às populações que ocupam tradicionalmente territórios de conservação da natureza. Revista do Direito Público. Londrina, v.9, n.3, p.197-222, set./dez.2014. DOI: 10.5433/1980511X.2014v9n3p197. 